\title{
Componentes primários e secundários do rendimento de óleo de pinhão-manso
}

\author{
Primary and secondary yield components of the oil in physic nut (Jatropha curcas L.)
}

\author{
Victor Mouzinho Spinelli' ${ }^{\mathrm{I}}$ Rodrigo Barros Rocha ${ }^{\mathrm{II}}$ André Rostand Ramalho ${ }^{\mathrm{II}}$ \\ Alaerto Luiz Marcolan ${ }^{\text {II }}$ José Roberto Vieira Júnior ${ }^{\text {II }}$ Cléberson de Freitas Fernandes ${ }^{\text {II }}$ \\ Júlio Sancho Linhares Teixeira MilitãoI Luiz Antônio dos Santos Dias ${ }^{\text {III }}$
}

\section{RESUMO}

A definição dos critérios para seleção de materiais é especialmente importante para o cultivo do pinhão-manso (Jatropha curcas L.), pois subsidia a caracterização dos ideótipos mais adequados para o plantio e o progresso genético com a prática da seleção. $O$ objetivo deste trabalho foi estimar, por meio de análise de trilha com diagrama em cadeia, os efeitos diretos $e$ indiretos de sete características vegetativas $e$ quatro características de qualidade da matéria-prima sobre o rendimento de óleo de pinhão-manso com 38 meses de cultivo. A produtividade de grãos e o teor de óleo apresentaram efeito direto e positivo sobre o rendimento de óleo, e o volume de copa mostrou-se como um dos principais componentes de efeito indireto e positivo sobre a variável principal. $\mathrm{Na}$ população de melhoramento avaliada, as estimativas dos efeitos diretos e indiretos indicaram que a seleção de plantas de maior rendimento de óleo deve considerar genótipos de maior produtividade de grãos e maior volume de copa, mantendo-se a variabilidade para as outras características avaliadas.

Palavras-chave: Jatropha curcas L., análise de trilha, produtividade, teor de óleo.

\section{ABSTRACT}

The definition of the most suitable plant selection criteria is especially important for Jatropha curcas L. as subsidies the genetic progress estimates and the ideotype characterization, described in terms of the traits that are thought to enhance genetic yield potential. The objective of this study was to estimate the direct and indirect effects of seven vegetative traits and four seed quality traits on $\mathbf{J}$. curcas oil yield. The traits grain yield and the weight of the nuts showed direct and positive effect on the oil yield. The tree volume showed the major indirect and positive effect on the main variable through grain yield. The development of $\mathbf{J}$. curcas with higher oil yield in the evaluated population has to consider the selection of plants with higher yield and tree volume, maintaining the variability of the grain quality traits.

Key words: Jatropha curcas L., path analysis, oil yield.

\section{INTRODUÇÃO}

O pinhão-manso é uma planta perene da família das Euforbiáceas, particularmente resistente às condições adversas de clima e solo, cujo potencial para produção de óleo tem sido considerado (HELLER, 1996). Nativo da América Central, o pinhão-manso vem sendo plantado em regiões tropicais e subtropicais de todo o mundo (BELTRÃO \& OLIVEIRA, 2007).

Historicamente, essa oleaginosa tem sido utilizada em cultivo tanto para proteção do solo contra erosão como para estabelecimento de cercas vivas, e suas folhas, seu látex, sua casca e seu óleo são bem conhecidos da medicina tradicional. Na atualidade, seu óleo vem sendo considerado matéria-prima potencial para substituição dos combustíveis fósseis (OPENSHAW, 2000). Considerado ainda como uma espécie em domesticação, não existem variedades comerciais e o estabelecimento dos critérios mais apropriados para a seleção de materiais é especialmente

'Universidade Federal de Rondônia, 76815-800, Porto Velho, RO, Brasil.

IIEmpresa Brasileira de Pesquisa Agropecuária, Centro de Pesquisa Agroflorestal de Rondônia, 76815-800, Porto Velho, RO, Brasil. E-mail: rodrigo@cpafro.embrapa.br.*Autor para correspondência.

IIIDepartamento de Fitotecnia, Universidade Federal de Viçosa, Viçosa, MG, Brasil. 
importante para esse cultivo (DIAS et al., 2007; RAO et al., 2008).

A análise de trilha, proposta originalmente por WRIGHT (1923), permite desdobrar os coeficientes de correlação em seus efeitos diretos e indiretos sobre uma característica principal (CRUZ et al., 2004) e sua utilização apropriada depende do conjunto de caracteres estudados e da elaboração de um diagrama de causa e efeito, que representa a relação dos caracteres sobre uma característica principal. O rendimento de óleo do pinhão-manso é o principal produto desse cultivo, e o volume de óleo produzido pela planta depende da associação das características produtivas e vegetativas em um determinado ambiente.

Com exceção das questões analíticas da extração do óleo, seja pela prensagem ou pelo uso de solventes, o rendimento desse processo depende essencialmente do teor de óleo e do volume de matériaprima utilizado na extração. Já em relação aos componentes de produção dessa oleaginosa, o rendimento de óleo depende da expressão de características vegetativas que se diferenciam, principalmente, em relação ao número de ramos, a projeção da copa, a altura e o volume de copa por árvore, e características produtivas, tais como, a produção de grãos, o peso de grãos, o peso de amêndoas, o peso de casca e o teor de óleo nos grãos (RAO et al., 2008).

De acordo com LAVIOLA \& DIAS (2008) e

TOMINAGA et al. (2007), em média, espera-se que o cultivo produza $0,1,0,5,2$ e $4 \mathrm{~kg}_{\text {planta }}{ }^{-1}$ de sementes no primeiro, segundo, terceiro e quarto anos de cultivo, respectivamente, estabilizando sua produtividade entre o terceiro e o quarto ano. DRUMOND et al. (2010) caracterizaram genótipos responsivos a melhoria ambiental que produziram aos 12 meses de plantio 2,12 kg arv ${ }^{-1}$ de grãos em sistema irrigado.

Poucos trabalhos caracterizaram a associação das características produtivas em pinhãomanso. RAO et al. (2008) observaram valores de correlação positiva entre a produtividade de grãos e a altura da planta, o número de ramos e a proporção de flores masculinas e femininas. O número de ramos foi a característica que apresentou maior associação com a produtividade de grãos em acessos de 36 meses de plantio. HELLER (1996) e GINWAL et al. (2005) observaram a ocorrência de correlações positivas e de alta magnitude entre peso das sementes e teor de óleo, assim como correlações negativas entre peso das sementes e teor de fibras e conteúdo de cinzas nas sementes. RAO et al. (2008) também observaram valores significativos de correlação entre o peso de sementes e o teor de óleo, de maneira similar aos resultados obtidos por ROCHA et al. (2008), que quantificaram maior variabilidade do peso da amêndoa, um dos principais componentes do peso de grãos.

O objetivo deste trabalho foi quantificar os efeitos diretos e indiretos de características vegetativas e de qualidade da matéria-prima sobre o rendimento de óleo de pinhão-manso, visando a fornecer subsídios para o melhoramento genético dessa espécie.

\section{MATERIAIS E MÉTODOS}

\section{Experimento de campo}

Foram caracterizadas 236 plantas selecionadas ao acaso dentro de uma população de pinhão-manso com 38 meses de cultivo, em plantio localizado no município de Ariquemes-Rondônia (RO) (latitude 9`55’24.50S; longitude 63²’15.58O e 142m de altitude). O clima da região é tropical tipo Aw, quente e úmido, apresenta período seco bem definido, com ocorrência de déficit hídrico nos meses de junho, julho, agosto e setembro, temperatura média anual de $25^{\circ} \mathrm{C}$, precipitação média anual de $2354 \mathrm{~mm}$ e evapotranspiração média anual de 851mm, (BRASIL, 1992). O solo da área experimental é um Latossolo Vermelho Amarelo Distrófico, com textura muito argilosa.

O espaçamento adotado no cultivo foi de 2x3m, sendo o plantio efetuado em covas com mudas de um mês de crescimento em viveiro, formadas em sacolas plásticas de dois litros. Cada cova recebeu $100 \mathrm{~g}$ de superfosfato simples. No segundo ano de plantio, foi realizada a calagem superficial da área total com a aplicação de quatro toneladas de calcário por hectare (P.R.N.T 60\%). A adubação iniciou-se a partir do segundo ano, com a aplicação de $50 \mathrm{~g}$ de $\mathrm{N}, 60 \mathrm{~g}$ de $\mathrm{P}_{2} \mathrm{O}_{5}$ e $40 \mathrm{~g}$ de $\mathrm{K}_{2} \mathrm{O}$ em cobertura, três meses antes das principais colheitas do cultivo na região, que acontecem nos meses de junho e dezembro.

\section{Avaliações das plantas}

Antes da colheita realizada aos 38 meses após o plantio, os seguintes caracteres vegetativos foram medidos: altura de plantas $\left(\mathrm{m} \mathrm{arv}^{-1}\right)$, número de ramos secundários, número de ramos terciários, projeção da copa no sentido do maior espaçamento (m $\left.\operatorname{arv}^{-1}\right)$, projeção da copa no sentido do menor espaçamento ( $\mathrm{m}$ arv $\left.{ }^{-1}\right)$ e volume de copa $\left(\mathrm{m}^{3} \operatorname{arv}^{-1}\right)$. A altura das plantas e a projeção da copa foram mensuradas com régua de $2,5 \mathrm{~m}$ graduada em centímetros. O volume de copa foi estimado pela aproximação do volume de um cilindro de base elíptica:

$V_{\text {copa }}=\left(\pi \cdot \frac{D_{1}}{2} \cdot \frac{D_{2}}{2}\right) h$, em que $\mathrm{v}_{\text {copa }}:$ volume de copa $\left(\mathrm{m}^{3}\right), \pi$ :

3,14159, $P_{1}$ : projeção da copa no maior espaçamento

Ciência Rural, v.40, n.8, ago, 2010. 
(m), $P_{2}$ : projeção da copa no menor espaçamento (m) e $h$ : altura (m). Com a colheita do plantio, foram avaliadas individualmente as seguintes características: produtividade de grãos $\left(\mathrm{kg} \mathrm{arv}^{-1}\right)$, peso de casca (g grão ${ }^{-1}$ ), peso de amêndoas (g grão ${ }^{-1}$ ), teor de óleo (\%) e rendimento de óleo por árvore $\left(\mathrm{ml} \mathrm{arv}^{-1}\right)$.

As características de qualidade da matériaprima foram avaliadas no Laboratório de Extração de Óleos da Universidade Federal de Rondônia (UNIR), em Porto Velho, RO. Os procedimentos de extração de óleo foram realizados com o trituramento das sementes inteiras e dos albúmens, separadamente, com quantificação gravimétrica. Ambos foram caracterizados segundo as normas do INSTITUTO ADOLFO LUTZ (1985), que compreendem umidade e cinzas. As bateladas de extrações do óleo foram realizadas utilizando duas réplicas por amostra em extrator de Soxhlet com hexano, como solvente, com um tempo de quatro horas de extração e cerca de $200 \mathrm{~g}$ de amostra. Após a extração, foram identificadas amostras que apresentaram diferença entre repetições igual ou superior a $2 \%$ do teor de óleo, que tiveram seu teor novamente quantificado em uma nova batelada.

Diagnóstico de multicolinearidade e análise de trilha

As estimativas da correlação fenotípica entre as características avaliadas foram estimadas com os valores do quadrado médio esperado (QME) obtidos na análise de variância, conforme descrito por CRUZ et al. (2004), e a sua significância foi avaliada por meio do teste $\mathrm{t}$, com $n$ - 2 graus de liberdade, sendo n o número de genótipos avaliados. Foi interpretado o grau de multicolinearidade da matriz singular $X{ }^{\prime} X$ com base no número de condição (NC), de acordo com classificação proposta por MONTGOMERY \& PECK (1981).

As estimativas dos efeitos diretos e indiretos das variáveis explicativas sobre a variável principal foram obtidas pela resolução do sistema linear (CRUZ et al., 2004): $\hat{\beta}=\left(X^{\prime} X\right)^{-1} X^{\prime} Y$, em que: $\hat{\beta}=$ é um vetor coluna contendo as estimativas dos coeficientes de trilha, $X^{\prime} X=$ é uma matriz não singular das correlações entre as variáveis explicativas e $X^{\prime} Y=$ é um vetor coluna das correlações entre a variável principal e as variáveis explicativas. As relações entre os componentes de produção foram interpretadas de acordo com um diagrama causal que contempla componentes primários e secundários de produção considerando a relação lógica, aditiva entre as variáveis, conforme metodologia proposta por CRUZ et al. (2004) (Figura 1).

\section{RESULTADOS E DISCUSSÃO}

Antes da decomposição das relações de causa e efeito entre os componentes de produção, avaliou-se o grau de multicolinearidade da matriz de correlações padronizadas entre os caracteres avaliados. A interpretação do número de condição (NC) indicou a ocorrência de multicolinearidade severa no conjunto inicial de características ( $\mathrm{NC}=5022$ ). O descarte das características peso de óleo nos grãos e peso de grãos resultou na redução do número condição (NC=96), que, segundo MONTGOMERY \& PECK (1981), não indica problemas para a análise de trilha (COIMBRA, et al., 2005).

No diagrama causal, as setas que partem do rendimento do óleo indicam os componentes primários, definidos pelo teor de óleo, produtividade de grãos e volume de copa. A relação entre os componentes secundários: peso da amêndoa, peso da casca, altura, projeção da copa no sentido de menor espaçamento, projeção da copa no sentido do maior espaçamento e número de ramos é representada pelas setas que se inter-relacionam (Figura 1).

Observou-se que os componentes de produção influenciaram diferencialmente, de maneira direta ou indireta, o produto principal do cultivo (Tabela 1). A produtividade de grãos e o peso de amêndoas apresentaram efeito direto e positivo sobre a característica principal. A soma dos efeitos diretos e indiretos da produtividade de grãos foi superior à soma dos efeitos das outras características (Tabela 1).

A magnitude do efeito direto da produtividade de grãos sobre o rendimento de óleo mostrou que a produção de grãos foi a característica mais importante para a seleção de plantas de rendimento de óleo superior. $\mathrm{O}$ valor observado do coeficiente de determinação indica que fração representativa da variabilidade da característica principal do cultivo foi explicada pela variação das características primárias do diagrama, indicando eficiência na decomposição das relações de causa e efeito dos componentes de produção dessa oleaginosa (AMORIM et al., 2008).

Dos três componentes primários de produção, o volume de copa apresentou o menor efeito direto sobre o rendimento de óleo. Caracteres com valores de correlação considerados elevados (acima de 0,7$)$, mas com baixo efeito direto indicam que a seleção truncada na característica auxiliar pode não proporcionar ganhos satisfatórios na característica principal, nesse caso, o rendimento de óleo (RESENDE, 2002), sendo apropriado à utilização de índices de seleção considerando os caracteres de efeito indiretos significativos.

Ciência Rural, v.40, n.8, ago, 2010. 


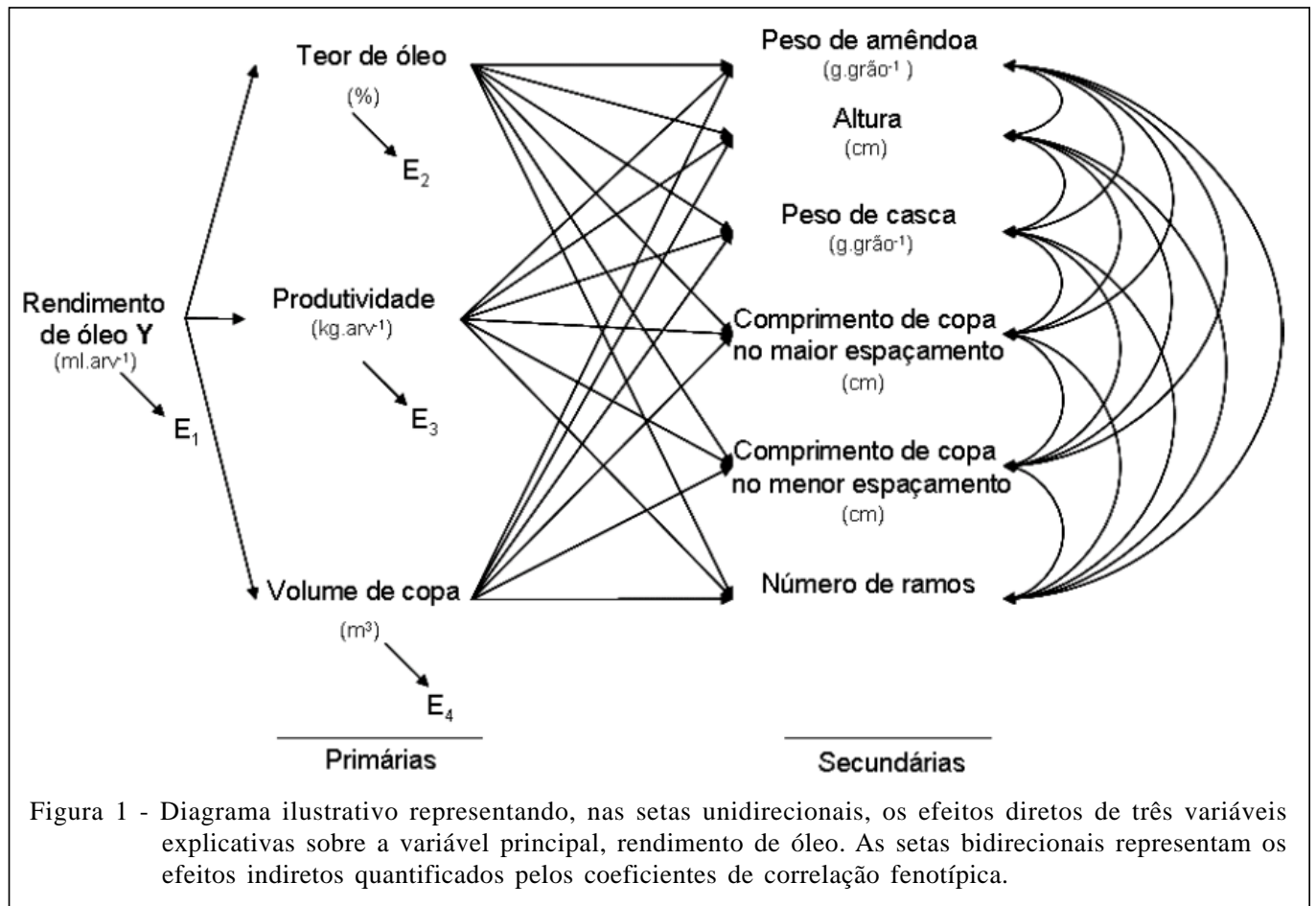

Apesar do pequeno efeito direto, o volume de copa foi o principal componente da produtividade de grãos (Tabela 1). Em geral, a arquitetura de copa é considerada uma característica importante para o cultivo do pinhão-manso e trabalhos vem sendo realizados com o objetivo de descrever práticas de poda mais apropriadas para esse cultivo. No entanto, poucos trabalhos avaliaram a diferença entre a arquitetura das plantas considerando conjuntamente a relação entre a projeção e a altura da copa.

A avaliação do volume de copa permitiu quantificar o crescimento das plantas tendo em vista a variabilidade observada em campo e o efeito da compensação de crescimento da árvore, uma vez que foram observadas árvores altas de copas estreitas e árvores baixas de copas mais largas. O volume de copa apresentou efeito direto superior ao dos seus componentes individuais sobre a produtividade de grãos, mostrando-se mais importante do que a altura e a projeção da copa para caracterização de genótipos superiores.

Em relação aos efeitos dos componentes secundários sobre os primários, observou-se que os efeitos totais dos componentes secundários explicam, com bom ajuste, a variação do volume de copa e, com menor ajuste, o teor de óleo e a produtividade de grãos. A projeção da copa no sentido do maior espaçamento apresentou o maior efeito direto tanto para volume de copa, quanto para a produtividade de grãos, em comparação com a projeção da copa no sentido do menor espaçamento (Tabela 2). A utilização do

Tabela 1 - Estimativas dos efeitos diretos e indiretos dos três componentes primários, produtividade, teor de óleo e volume de copa sobre o rendimento de óleo em pinhão-manso.

\begin{tabular}{|c|c|c|c|c|c|}
\hline \multirow{2}{*}{ Característica } & \multirow{2}{*}{ Efeito Direto } & \multirow[b]{2}{*}{ Produtividade de grãos } & \multirow[b]{2}{*}{ Teor de óleo } & \multirow[b]{2}{*}{ Volume de copa } & \multirow{2}{*}{ Efeitos totais } \\
\hline & & & & & \\
\hline Produtividade de grãos & 0,923 & & $-0,006$ & $-0,002$ & 0,915 \\
\hline Teor de óleo & 0,176 & $-0,035$ & & 0,001 & 0,142 \\
\hline Volume de copa & $-0,005$ & 0,429 & $-0,021$ & & 0,403 \\
\hline $\mathrm{R}^{2}$ & 0,9048 & & & & \\
\hline Efeito Residual & 0,0724 & & & & \\
\hline
\end{tabular}

$R^{2}$ : Coeficiente de determinação 
Tabela 2 - Estimativas dos efeitos diretos e indiretos das características secundárias altura, projeção da copa no sentido do menor espaçamento, projeção da copa no sentido do maior espaçamento, número de ramos, peso de casca e peso de amêndoas sobre as características primárias produtividade, teor de óleo e volume de copa do pinhão-manso.

\begin{tabular}{|c|c|c|c|c|c|c|c|c|}
\hline \multirow{2}{*}{ Característica } & \multirow{2}{*}{ Efeito Direto } & \multicolumn{6}{|c|}{---------------------------------------Efeitos indiretos------------------------------------- } & \multirow{2}{*}{$\begin{array}{c}\text { Efeitos } \\
\text { totais }\end{array}$} \\
\hline & & Altura & P1 & P2 & Ramos & Peso casca & Peso amênd. & \\
\hline \multicolumn{9}{|c|}{ 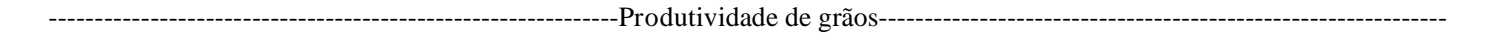 } \\
\hline Altura & 0,059 & & $-0,074$ & 0,218 & 0,091 & $-0,001$ & $-0,007$ & 0,286 \\
\hline $\mathrm{P} 1$ & $-0,142$ & 0,031 & & 0,2552 & 0,102 & 0,008 & $-0,003$ & 0,252 \\
\hline $\mathrm{P} 2$ & 0,353 & 0,033 & $-0,102$ & & 0,107 & $-0,001$ & $-0,006$ & 0,384 \\
\hline Ramos & 0,211 & 0,025 & $-0,068$ & 0,178 & & $-0,014$ & $-0,012$ & 0,320 \\
\hline Peso de casca & 0,162 & $-0,001$ & $-0,007$ & $-0,001$ & $-0,019$ & & 0,080 & 0,214 \\
\hline Peso amênd. & 0,097 & $-0,004$ & 0,001 & $-0,022$ & $-0,027$ & 0,1337 & & 0,178 \\
\hline $\mathrm{R}^{2}$ & 0,236 & & & & & & & \\
\hline Efeito Residual & 0,874 & & & & & & & \\
\hline Altura & 0,094 & & $-0,096$ & 0,682 & $-0,116$ & 0,003 & $-0,04$ & $-0,087$ \\
\hline $\mathrm{P} 1$ & $-0,082$ & 0,0493 & & 0,0866 & $-0,129$ & $-0,023$ & $-0,079$ & $-0,178$ \\
\hline $\mathrm{P} 2$ & 0,121 & 0,0533 & & & $-0,135$ & 0,001 & $-0,0364$ & 0,004 \\
\hline Ramos & $-0,268$ & 0,041 & $-0,088$ & 0,061 & & 0,043 & $-0,076$ & $-0,287$ \\
\hline Peso de casca & $-0,480$ & $-0,001$ & $-0,009$ & $-0,001$ & 0,238 & & 0,496 & 0,243 \\
\hline Peso amênd. & 0,600 & $-0,006$ & 0,006 & $-0,007$ & 0,034 & $-0,397$ & & 0,230 \\
\hline $\mathrm{R}^{2}$ & 0,414 & & & & & & & \\
\hline Efeito Residual & 0,685 & & & & & & & \\
\hline Altura & $-0,082$ & & 0,2132 & 0,3488 & 0,0221 & $-0,001$ & 0,004 & 0,505 \\
\hline $\mathrm{P} 1$ & 0,405 & $-0,043$ & & 0,443 & 0,025 & 0,004 & 0,002 & 0,836 \\
\hline $\mathrm{P} 2$ & 0,614 & $-0,047$ & 0,2927 & & 0,0258 & $-0,001$ & 0,004 & 0,889 \\
\hline Ramos & 0,051 & $-0,036$ & 0,195 & 0,3101 & & $-0,008$ & 0,007 & 0,519 \\
\hline Peso de casca & 0,091 & & 0,0191 & $-0,001$ & $-0,005$ & 0,001 & $-0,047$ & 0,058 \\
\hline Peso amênd. & $-0,057$ & 0,006 & $-0,012$ & $-0,038$ & $-0,007$ & 0,075 & & $-0,033$ \\
\hline $\mathrm{R}^{2}$ & 0,877 & & & & & & & \\
\hline Efeito Residual & 0,351 & & & & & & & \\
\hline
\end{tabular}

$R^{2}$ : Coeficiente de determinação, P1: projeção da copa no menor espaçamento, P2: projeção da copa no maior espaçamento.

espaçamento desigual entre linhas (3x2m) resultou no maior desenvolvimento de ramos e crescimento desigual da copa no sentido do maior espaçamento.

Uma das estratégias que vem sendo considerada para reduzir os custos de colheita dessa oleaginosa é o aumento da produtividade por árvore. A limitação no crescimento da planta avaliado no menor espaçamento do plantio indica que práticas de manejo que objetivam o aumento da produtividade por árvore em plantios com três ou mais anos de cultivo devem considerar a utilização de espaçamentos mais amplos e o maior desenvolvimento de copa da árvore.

Entre os componentes secundários, o peso de casca e o peso de amêndoas apresentaram associação com o componente primário teor de óleo (Tabela 2), e de maneira geral observou-se que os caracteres vegetativos não apresentaram associação com esse componente. Desta forma, considera-se a manutenção da variabilidade dessas características na seleção dos materiais mais produtivos para permitir ganhos em novos ciclos de seleção. O menor ajuste das características secundárias à variabilidade da característica principal, rendimento de óleo, também sugere uma adequação do diagrama de associação entre os componentes primários e secundários (Tabela 3).

A quantificação da resposta correlacionada com a prática da seleção é um dos principais benefícios do estudo da associação de características produtivas, permitindo utilizar as estimativas dos efeitos diretos e indiretos na confecção de índice de seleção para obtenção de ganhos em rendimento de óleo pelo aumento da produtividade, do volume de copa mantendo a variabilidade genética para teor de óleo. 
Tabela 3 - Estimativas dos efeitos diretos e indiretos das características secundárias altura, projeção da copa no sentido do menor espaçamento, projeção da copa no sentido do maior espaçamento, número de ramos, peso de casca e peso de amêndoas sobre a variável principal, rendimento de óleo.

\begin{tabular}{|c|c|c|c|c|c|c|c|c|}
\hline Característica & Efeito Direto & Altura & $\mathrm{P} 1$ & $\mathrm{P} 2$ & Ramos & $\begin{array}{l}\text { Peso } \\
\text { casca }\end{array}$ & $\begin{array}{c}\text { Peso } \\
\text { amênd. }\end{array}$ & Efeitos totais \\
\hline- & (1) & 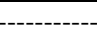 & ---Rendi & o de óleo & --------- & ----------- & --------- & ------------ \\
\hline Altura & 0,08 & & $-0,086$ & 0,201 & 0,0746 & $-0,0001$ & $-0,013$ & 0,256 \\
\hline P1 & $-0,064$ & 0,042 & & 0,156 & 0,083 & 0,004 & $-0,006$ & 0,215 \\
\hline P2 & 0,353 & 0,045 & $-0,012$ & & 0,087 & $-0,001$ & $-0,012$ & 0,354 \\
\hline Ramos & 0,172 & 0,035 & $-0,079$ & 0,1787 & & $-0,008$ & $-0,024$ & 0,275 \\
\hline Peso de casca & 0,092 & $-0,001$ & $-0,007$ & $-0,007$ & $-0,015$ & & 0,15668 & 0,149 \\
\hline Peso amênd. & 0,189 & $-0,005$ & 0,0049 & $-0,022$ & $-0,022$ & 0,0765 & & 0,222 \\
\hline $\mathrm{R}^{2}$ & 0,32 & & & & & & & \\
\hline Efeito Residual & 0,78 & & & & & & & \\
\hline
\end{tabular}

$R^{2}$ : Coeficiente de determinação, P1: projeção da copa no menor espaçamento, P2: projeção da copa no maior espaçamento.

\section{CONCLUSÃo}

Os resultados deste trabalho indicam que plantas de maior produtividade de grãos e de maior volume de copa foram importantes para o desenvolvimento de materiais de alto rendimento de óleo e que a seleção de plantas deve considerar, além da maior relevância dessas características na atribuição de pesos, a manutenção da variabilidade das características de qualidade, tais como o teor de óleo na semente, para subsidiar a obtenção de ganhos futuros.

\section{AGRADECIMENTOS}

Os autores gostariam de agradecer ao Conselho Nacional de Desenvolvimento Científico e Tecnológico (CNPq), pelo apoio dado ao projeto "Desenvolvimento de tecnologia para a produção agrícola energética no Estado de Rondônia”.

\section{REFERÊNCIAS}

AMORIM, E.P. et al. Correlações e análise de trilha em girassol. Bragantia, Campinas, v.67, n.2, p.307-316, 2008. Disponível em: <http://www.scielo.br>. Acesso em: 28 jan. 2010.

BRASIL. Ministério da Agricultura e da Reforma Agrária. Departamento Nacional de Meteorologia. Normais climatológicas: 1961-1990. Brasília, DF, 1992. 84p.

BELTRÃO, N.E.M de.; OLIVEIRA, M.I.P. Oleaginosas potenciais do Nordeste para a produção de biodiesel. Campina Grande: EMBRAPA, 2007. (Documentos Embrapa n.177. ISSN 0103-0205).

COIMBRA, J.R.M. et al. Conseqüências da multicolinearidade sobre a análise de trilha em canola. Ciência Rural, Santa
Maria, v.35, n.2, p.347-352, 2005. Disponível em: <http:// www.scielo.br>. Acesso em: 28 jan. 2010. doi: 10.1590/S010384782005000200015 .

CRUZ, C.D. et al. Modelos biométricos aplicados ao melhoramento genético. 3.ed. Viçosa: UFV, 2004. 480p.

DIAS, L.A.S. et al. Cultivo de pinhão manso (Jatropha curcas). Viçosa: UFV, 2007. 40p.

DRUMOND, M.A. et al. Desempenho agronômico de genótipos de pinhão manso no semiárido pernambucano. Ciência Rural, Santa Maria, v.40, n.1, p.44-47, 2010. Disponível em: <http://www.scielo.br>. Acesso em: 28 jun. 2010. doi: 10.1590/S0103-84782009005000229.

GINWAL H.S. et al. Seed source variation in morphology, germination and seedling growth of Jatropha curcas (L.), in Central India. Silvae Genetica, Frankfurt, v.54, p.76-80, 2005. Disponível em: <http://www.bfafh.de/inst2/sg-pdf/ 54_2_76.pdf >. Acesso em: 28 jan. 2010.

HELLER, J. Physic nut (Jatropha carcass): promoting the conservation and use of underutilized and neglected crops. Rome: Institute of Plant Genetics and Crop Plant Research, 1996. 66p. Disponível em: <http://www.bionica.info/biblioteca >. Acesso em: 28 jan. 2010.

INSTITUTO ADOLFO LUTZ. Normas analíticas do Instituto Adolfo Lutz. 3.ed. São Paulo: IMESP, 1985. V.1, 533p.

LAVIOLA, B.G.; DIAS, L.A.S. Teor e acúmulo de nutrientes em folhas e frutos de pinhão-manso. Revista Brasileira Ciência do Solo, Viçosa, v.32, p.1969-1975, 2008. Disponível em: <http://www.scielo.br>. Acesso em: 28 jun. 2010. doi: 10.1590/S0100-06832007000600021. 
MONTGOMERY, D.C.; PECK, E.A. Introduction to linear regression analysis. New York: J. Wiley, 1981. 504p.

OPENSHAW, K. A review of Jatropha curcas: an oil plant of unfulfilled promise. Biomass and Bioenergy, Alberdee, v.19, p.1-15, 2000. Disponível em: <http://www.sciencedirect.com>. Acesso em: 28 jan. 2010.

RAO G.R., et al. Genetic associations, variability and diversity in seed characters growth, reproductive phenology and yield in Jatropha curcas (L.) accessions. Trees, Berlin, v.22, p.697709, 2008. Disponível em: <http://www.springerlink.com>. Acesso em: 28 jan. 2010. doi: 10.1007/s00468-008-0229-4.
RESENDE, M.D.V. Genética biométrica e estatística no melhoramento de plantas perenes. Brasília, DF: Embrapa Informação Tecnológica, 2002. 975p.

ROCHA R.B. et al. Avaliação da variabilidade do peso médio de sementes de pinhão manso (Jatropha curcas L.). Rondônia: EMBRAPA, 2008. (Circular Técnica, 104. ISSN 0103-9334)

TOMINAGA, N. et al. Cultivo de pinhão-manso para produção de biodiesel. Viçosa: CPT, 2007. 220p.

WRIGHT, S. Theory of path coefficients. Genetics, New York, v.8, p.239-285, 1923. 